\title{
The application of FT-IR spectroscopy in discrimination of differently originated and aged whisky
}

\author{
Katarzyna Sujka' ${ }^{1}$ Piotr Koczoń ${ }^{2}$
}

Received: 4 April 2018 / Accepted: 16 June 2018 / Published online: 25 June 2018

(c) The Author(s) 2018

\begin{abstract}
The rapid, simple, and non-destructive analytical procedure for discrimination and authentication of whiskies originating from Scotland, Ireland and USA due to their origin as well as time of maturation (two, three, six and twelve years) is presented. Combination of data from infrared spectroscopy with statistical analysis was used to construct eight discriminant models. Models obtained allowed to distinguish Scottish, Irish, and American whiskies and 2 and 3 years old beverages from 6 and 12 years old whiskies. Results show that $100 \%$ of samples were correctly classified in models discriminating American and Scottish whiskies or 2-year-old and 6-year-old American whiskies. American whiskies were classified correctly in all models which may suggest its considerable chemical difference compared to whisky produced in Scotland or Ireland. Constructed in current paper discriminant models can be used to identify unknown samples of whisky in terms of origin or age.
\end{abstract}

Keywords FT-IR spectroscopy $\cdot$ Whisky $\cdot$ Discriminant analysis $\cdot$ Classification $\cdot$ Year of aging

\section{Introduction}

Whisky is the most popular spirit beverage worldwide, produced everywhere in similar way. Starting material, i.e., cereal and water are processed to mash which is then converted to fermentable mass by action of enzymes that degraded starches present in mash. Next yeasts conduct fermentation and obtained mash is distillated. Fresh spirit is matured for a minimum 3 years in the case of Scottish and Irish whiskies, and 2 years in the case of USA products, before it is bottled as final whisky [1]. Only water and caramel (for coloring in Scottish and Irish whiskies) are permitted as an additives [2]. During maturation occurring in specific wooden barrels, substances responsible for detailed smell and taste are formed and then extracted into solution from barrel wood [3]. The complex, diverse, and specific aromas and flavors of whisky are characteristic for the place

Katarzyna Sujka

katarzyna_sujka@sggw.pl

1 Department of Food Technology, Faculty of Food Sciences, Warsaw University of Life Sciences, Nowoursynowska 159 C, 02-787 Warsaw, Poland

2 Department of Chemistry, Faculty of Food Sciences, Warsaw University of Life Sciences, Nowoursynowska 159 C, 02-787 Warsaw, Poland of its origin and technological process conducted, e.g., time of maturation [4].

The authenticity of the beverages, especially alcoholic beverages and foods is an important issue today. Falsifications and adulterations occur mostly in illegal factories, restaurants, bars, and other retailers. It unfavorably affects producers as well as consumers health [5]. High price whisky is most often subjected to adulterations. There are many ways to adulterate original product, e.g., diluting whisky with water or cheaper product or adding a mixture of water, chemically obtained or cane ethanol, caramel, dyes, and flavors to less expensive beverages $[6,7]$.

Analyses due to authenticity of spirit beverages are conducted with the use of advanced instrumental methods, e.g., gas chromatography, mass spectrometry, capillary electrophoresis, e-noses, and e-tongues [6, 8-13]. Except e-noses and e-tongues, above listed methods are relatively expensive, might be time consuming, and require highly skilled operators [14]. Nowadays simple, inexpensive, non-invasive, non-destructive, and portable instrumental techniques such as following spectral methods: near infrared (NIR), mid infrared (MIR) spectroscopy, and UV-Vis spectroscopy are required. Listed techniques that are exchangeable depend on the given specific case. It is hard to unambiguously state which one is better or worse as scientific publications inform about use of all of them in different cases presenting 
advantages and disadvantages of each one. However, the number of scientific publications presenting the application of optical spectroscopy in whisky [15-17] and other spirit beverages' [14] authenticity control and monitoring has increased recently. These techniques successfully compete with conventional analytical techniques.

Infrared spectroscopy informs indirectly about energy of oscillating molecules in the form of amount of energy absorbed/transmitted plotted against wavenumbers in IR spectrum. Intensities and wavenumbers of characteristic bands present in spectrum correlate with qualitative and quantitative composition of analyzed substances. Such correlation was used in our previous papers to discriminate vodkas produced form different raw materials [18] and distinguish selected spirit beverages [19, 20]. In the current paper, the aim was to use IR spectral data accompanied by discriminant analysis to classify different whiskies according to their trademark, origin, and age, by constructing and validating robust statistical models. The approach that uses spectral data from middle IR range for whisky classification has not been as to our knowledge extensively reported before which makes it novel. The novelty of current approach is analysis of whiskies due to different times of maturation together with whisky origin. Such combination has not been reported in the literature. The combination and comparison of Irish, Scotch, and American whiskies have been reported in literature once only [21].

\section{Materials and methods}

\section{Materials}

20 samples of whiskies were purchased from local stores in Warsaw, Poland. Studied whiskies were produced in Scotland (10), Ireland (5), and United States (5). The time of maturation was 2 (2), 3 (8), 6 (3), and 12 years (7), respectively. Every individual bottle was opened using bottle caps screw-metal or cork. Then, liquid was poured out to laboratory glass, i.e., ten vials of $10 \mathrm{~cm}^{3}$ volume. As 20 bottles were purchased and 10 samples were taken from each bottle, there were 200 samples altogether (100 for Scottish, 50 for Irish, and 50 for American). Analyzed samples included: 20 2-year-old whiskies, 80 3-year-old whiskies, 30 6-year-old whiskies, and 70 12-year-old whiskies.

\section{FT-IR spectroscopy}

FT-IR spectrometer (Perkin Elmer System 2000) with the DTGS (deuterated triglycine sulfate) detector was used to register spectra. The transmission technique with use of KRS crystals plates was applied to conduct ten scans for each of studied spirit beverage samples in the spectral range of
$4000-400 \mathrm{~cm}^{-1}$. The resolution was set to $2 \mathrm{~cm}^{-1}$ and the shift velocity was $2 \mathrm{~cm} \times \mathrm{s}^{-1}$. First, background spectrum was registered against air to further eliminate signals generated by water vapor and carbon dioxide from sample spectrum. Next, studied sample was placed between two KRS plates in the form of film. During registration, signals from working sample were rationed to background spectrum, so that signals from sample only were finally registered and presented on registered spectrum.

\section{Statistical analysis}

Discriminant model was constructed with the use of TQ Analyst software. Neither the noise removal nor any other pre-processing performance was performed; however, each spectrum was standardized by software itself. Spectral data were combined to produce statistically significant models. Cross validation was performed using sets for calibration and validation randomly defined by software. Models obtained with the use of various spectral ranges were tested to find best statistical values, i.e., number of factors, percent of misclassified samples, percent of variance, and performance index, and then characterized by those values. The Mahalanobis distance was used to screen a variety of whiskies. The software calculated mean spectrum out of all spectra used in calibration process. Then, distribution model was generated by estimating the variance of every single wavenumber taken from given range.

The algorithm for calculating the distance of a sample from the mean of a set of standards used the following equation:

$D^{2}=\left(X-X_{\text {avg }}\right)^{\mathrm{T}} S^{-1}\left(X-X_{\text {avg }}\right)$,

where $D$ equals the distance (as a scalar), $X$ is the data vector $(n \times 1), X_{\text {avg }}$ is the mean data vector $(n \times 1)$, $\mathrm{S}$ is the covariance matrix $(n \times \mathrm{n}),\left(X-X_{\text {avg }}\right)^{\mathrm{T}}$ denotes the transpose of $(\mathrm{X}$ $-\mathrm{X}_{\mathrm{avg}}$, and $\mathrm{N}$ is the number of data points in $X$.

\section{Results and discussion}

Classification of different whiskies according to their trademark, origin, and age, by constructing and validating robust statistical models, is only possible with the cooperative use of spectral data with discriminant analysis, statistical technique locating unknown sample in one of the classes of known samples most similar to unknown. This is done by compering distances from given class center expressed in Mahalanobis distance units. If Mahalanobis distance of unknown sample is smaller than distances calculated for standards used to produce given homologous group, then unknown sample is classified to this group (class). As a 
result, identification of sample due to desired parameter applied previously to calibrate model is obtained.

\section{IR spectra of whiskies}

Figures 1 and 2 show typical spectra with bands assigned to oscillating groups of atoms of components present in whisky. In mid-IR spectra of whisky, single strong band in the range of $3500-2800 \mathrm{~cm}^{-1}$ and five medium bands in the ranges of: 2400-2000, 1800-1550, 1150-1000, and $800-370 \mathrm{~cm}^{-1}$, respectively, are observed. Wide band near $3500 \mathrm{~cm}^{-1}$ corresponds to stretching vibrations of $\mathrm{O}-\mathrm{H}$ group, while bands at $1420-1330$ and $769-650 \mathrm{~cm}^{-1}$ are generated by deformations of $\mathrm{O}-\mathrm{H}$ group. Stretching and deformation vibrations of $\mathrm{C}-\mathrm{H}$ are observed in the range of $2970-2850$ and $1370-1340 \mathrm{~cm}^{-1}$, respectively. Very characteristic, intense symmetric stretching of carbonyl group $\mathrm{C}=\mathrm{O}$ in esters and carboxylic acids is observed in the range of $1700-1600 \mathrm{~cm}^{-1}$. Vibrations of the band O- C- C from primary alcohol esters are observed as band located in the range of $1164-1031 \mathrm{~cm}^{-1}$. In the range of $1600-1400 \mathrm{~cm}^{-1}$, bands generated by skeletal vibrations of aromatic ring are present [22, 23]. Bands present in studied whisky occur in similar spectral regions for every studied sample. This is due to high chemical similarity of studied samples. However, small but distinct differences occurring between IR
Fig. 1 IR spectra of analyzed whiskies; dark gray line-Irish whisky, light gray line-Scottish whisky, and black lineAmerican whisky
Fig. 2 IR spectra of analyzed whiskies; light gray line-3year-old Scottish, dark gray line-12-year-old Scottish, black dashed line-3-year-old Irish, light gray dashed line12-year-old Irish, and black line-6-year-old American
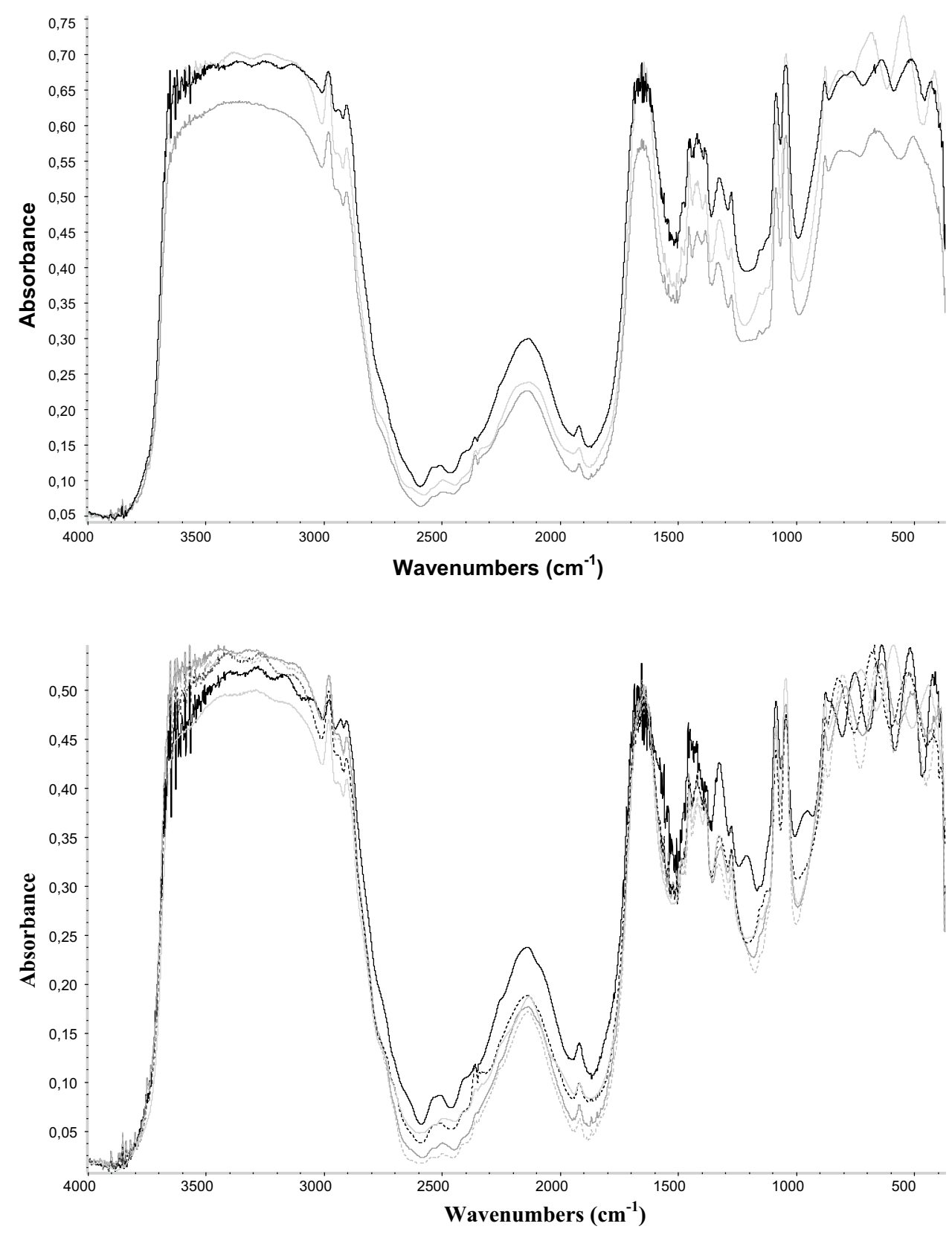
spectra of studied samples allow to differentiate samples due to desired factor.

\section{Discriminant models due to whisky origin}

Three types of whiskies were investigated: Scottish, Irish, and American. The group of Scottish whiskies contained 100 samples, while groups of Irish and American whiskies contained 50 samples, respectively. Samples were randomly divided into calibration and validation subgroups. The validation group contained $25 \%$ of all samples. First model (Model_1) included three studied whiskies. Then, studied whiskies were compared in pairs, i.e., American-Scotch (Model_2), American-Irish (Model_3), and Irish-Scottish (Model_4). Statistical parameters of models obtained for each pairs/three are presented in Table 1. Model_2 and Model_4 are presented in Figs. 3 and 4, respectively. Two distinct homogenous groups are clearly seen on both figures. Distances to American ( $y$ axis) and to Scottish ( $x$ axis) were calculated with application of principal component analysis that used spectral data from the following regions: 3100-1000 $\mathrm{cm}^{-1}$. Discriminant model for American and Scottish whiskies (Model_2) classified properly all samples, while model for American-Irish whisky (Model_3) misclassified two samples of Irish whiskies (they were classified as American). This model used spectral data from the following spectral range: $3100-1000 \mathrm{~cm}^{-1}$. In the case of Model_4 (Scottish-Irish), three samples of whiskies were classified incorrectly. American whiskies were classified correctly in all models which may suggest its considerably

Table 1 Statistical results of discrimination per origin

\begin{tabular}{|c|c|c|c|c|c|c|}
\hline Model & $\begin{array}{l}\text { Performance } \\
\text { index }\end{array}$ & $\begin{array}{l}\text { Number of } \\
\text { factors }\end{array}$ & $\%$ of variance & Spectral range & $\begin{array}{l}\text { Number of calibration } \\
\text { and validation test }\end{array}$ & $\begin{array}{l}\text { Number of incor- } \\
\text { rectly assigned } \\
\text { samples }\end{array}$ \\
\hline Model_1 & 82.1 & 10 & 99.0 & $3100-850 \mathrm{~cm}^{-1}$ & $150 / 50$ & 10 \\
\hline Model_2 & 85.0 & 10 & 100.0 & $3100-2800 \mathrm{~cm}^{-1}$ & $115 / 35$ & 0 \\
\hline Model_3 & 85.1 & 10 & 99.9 & $3100-1000 \mathrm{~cm}^{-1}$ & $75 / 25$ & 2 \\
\hline Model_4 & 83.0 & 10 & 96.3 & $3100-1100 \mathrm{~cm}^{-1}$ & $115 / 35$ & 3 \\
\hline
\end{tabular}

Fig. 3 Model_2-discrimination of American and Scottish whiskies by the use of Mahalanobis distances derived from spectral data from region: $3100-2800 \mathrm{~cm}^{-1}$. Gray diamond: Scottish whisky, black square: American whisky
Fig. 4 Model_4-discrimination of Irish and Scottish whiskies by the use of Mahalanobis distances derived from spectral data from region: 3100

$1100 \mathrm{~cm}^{-1}$. Gray diamond: Scottish whisky, black square: Irish whisky
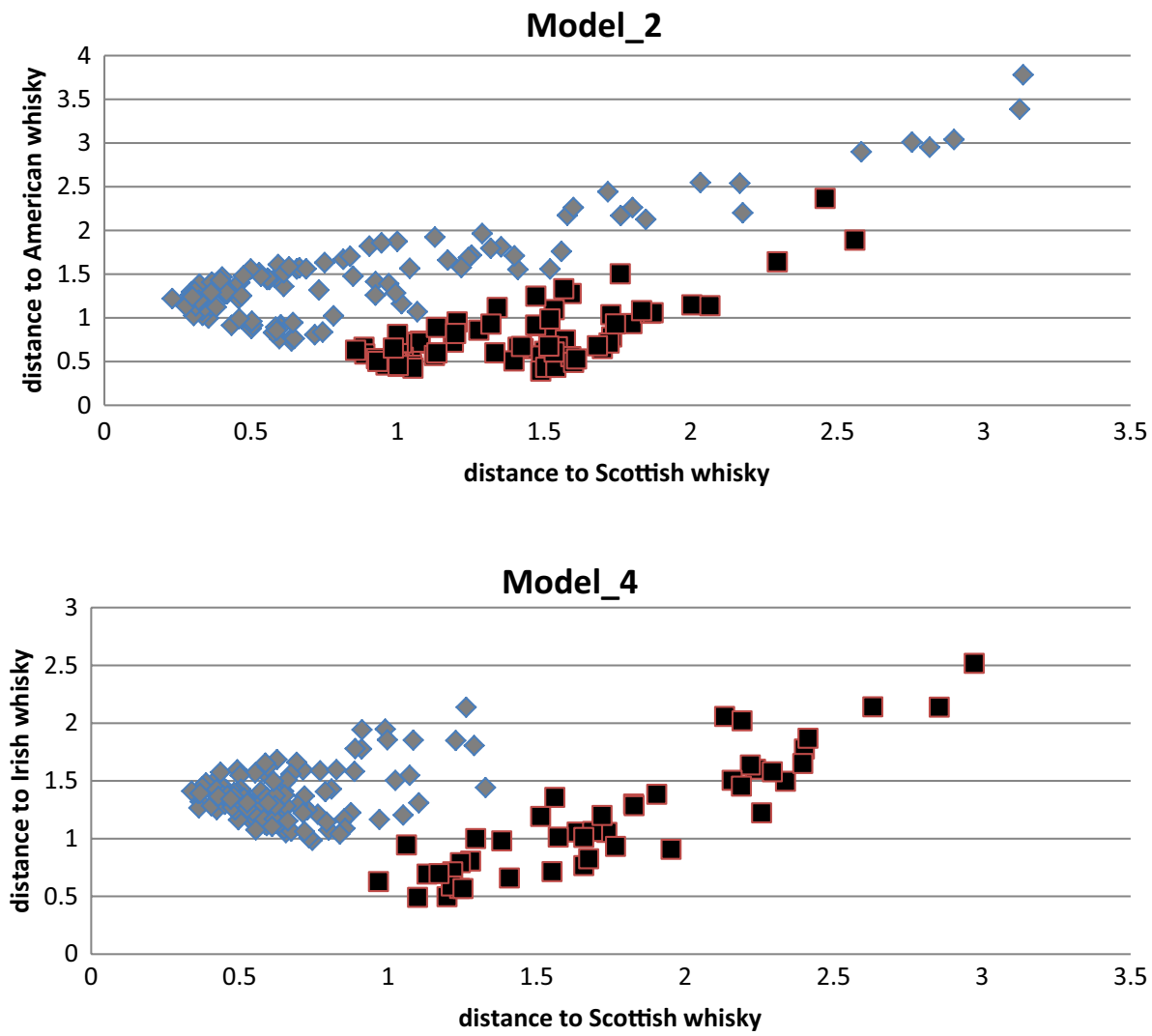
big chemical difference compared to whisky produced in Scotland or Ireland. Biological materials used for production, even though gathered from the same source usually differ in details. Chemical differences between final whiskies result from many factors, e.g., conditions applied in production process or type of raw materials used. Straight bourbon whisky is produced in USA mainly from corn, while in Europe the most popular raw materials are barley and wheat [24-26]. The similar observation was done by Wiśniewska et al. [21]. Discussed differences are expressed in spectral data that can be detected and managed by statistics. Performance index (PI) is a measure how accurately a method can classify the validation standards. In discriminant analysis to calculate the performance index, the average distance ratio algorithm is used. PI values range from 0 to 100 . Discriminant models constructed for currently studied whiskies obtained values range from 82.1 to 85.1 (see Table 1). The samples were classified according to linear algorithm contained combination of factors representing the percentage variance of IR spectra. Models were based on ten factors describing $96.3 \%$ of variance. To construct statistical models, IR spectral range from 3100 to $1000 \mathrm{~cm}^{-1}$ was used. The bands in this region correspond to vibrations of $\mathrm{C}=\mathrm{O}, \mathrm{C}-\mathrm{O}$, $\mathrm{O}-\mathrm{H}$, and $\mathrm{C}-\mathrm{H}$ group. The botanical origin of whiskies was analyzed by Wiśniewska et al. [21]. In their study, PLS-DA algorithm was applied to discrimination of Scottish, Irish,
Spanish, and American whiskies using IR spectra in the range $4000-650 \mathrm{~cm}^{-1}$.

\section{Discriminant models due to time of maturation}

Whiskies with different times of maturation were compared. American whiskies that were divided into two groups depend on time of maturation-2 or 6 years (Model_8). Irish (Model_6) and Scottish (Model_7) whiskies were divided into two groups as well: 3 years and 12 years, respectively. The results are presented in Table 2 . Model_6 and Model_8 are presented in Figs. 5 and 6. The highest PI value and the smallest number of misclassified samples were calculated with model for American whiskies (Model_8). 40 samples using this time spectral range of $3000-1100 \mathrm{~cm}^{-1}$ produced PI as high as 90.2 . This region again contains bands originated from oscillations of $\mathrm{C}=\mathrm{O}, \mathrm{C}-\mathrm{O}, \mathrm{O}-\mathrm{H}$, and $\mathrm{C}-\mathrm{H}$ groups, respectively. Irish and Scottish whiskies were discriminated with the use of spectral data from the range of $2400-500 \mathrm{~cm}^{-1}$. Model_6 and Model_7 were constructed with the use of 40 samples, and 1 and 2 samples were misclassified, in Model_6 and Model_7, respectively. Model_5 that was desired to differentiate all studied whiskies due to their age was constructed with the use of 100 Scottish and Irish whiskies samples and data from spectral range of

Table 2 Statistical results of discrimination per time of maturation

\begin{tabular}{llllcll}
\hline Model & Performance index & $\begin{array}{l}\text { Number of } \\
\text { factors }\end{array}$ & \% of variance & Spectral range & $\begin{array}{l}\text { Number of } \\
\text { calibration and } \\
\text { validation test }\end{array}$ & $\begin{array}{l}\text { Number of } \\
\text { incorrectly } \\
\text { assigned sam- } \\
\text { ples }\end{array}$ \\
\hline Model_5 & 88.2 & 10 & 96.1 & $2800-$ & $75 / 25$ & 3 \\
Model_6 & 89.4 & 10 & 97.5 & $2400-500 \mathrm{~cm}^{-1}$ & $30 / 10$ & 1 \\
Model_7 & 89.9 & 10 & 95.8 & $2400-500 \mathrm{~cm}^{-1}$ & $30 / 10$ & 2 \\
Model_8 & 90.2 & 10 & 99.0 & $3000-$ & $30 / 10$ & 0 \\
\hline
\end{tabular}

Fig. 5 Model_6-discrimination of Irish whisky by the use of Mahalanobis distances derived from spectral data from region: $2400-500 \mathrm{~cm}^{-1}$. Gray diamond: 3-year-old Irish whisky, black square: 12-yearold Irish whisky

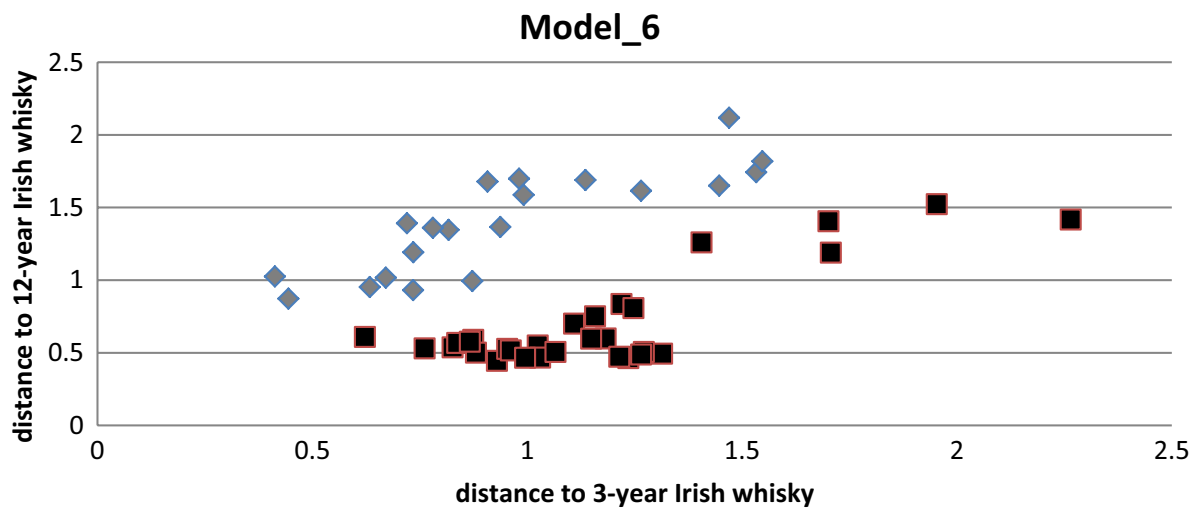


Fig. 6 Model_8-discrimination of American whisky by the use of Mahalanobis distances derived from spectral data from region $3000-1100 \mathrm{~cm}^{-1}$. Gray diamond: 2-year-old American whisky, black square: 6-year-old American whisky

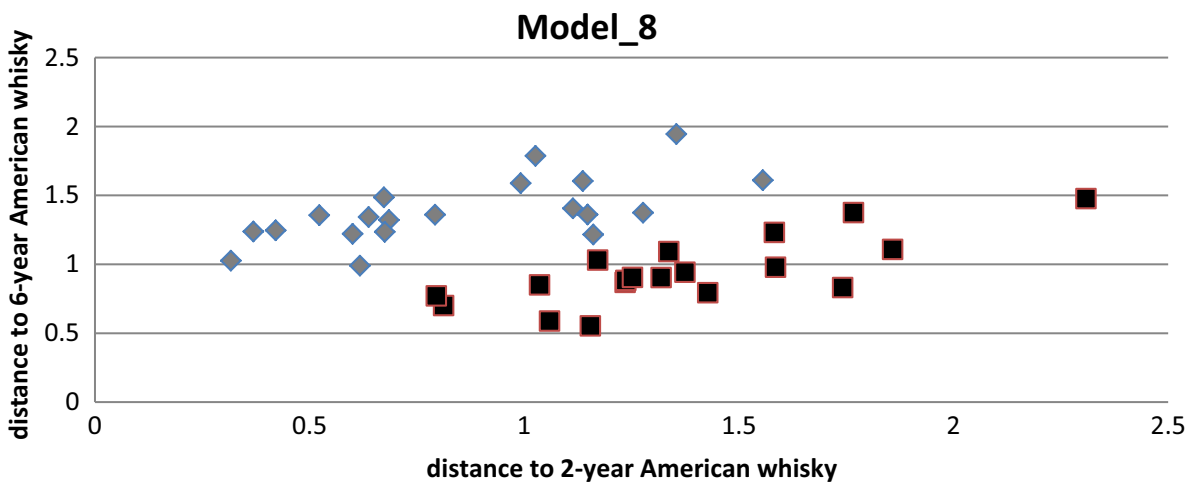

$2800-1000 \mathrm{~cm}^{-1}$. Validation set contained 25 randomly selected samples, out of which 3 were misclassified. Performance index for this model equals 88.2. The time of maturation significantly affects chemical composition of whisky. During maturation, substances extracted from the barrels enrich spirit beverage. Furthermore, some chemical reactions, e.g., mutual conversion of isomeric forms, oxidation/reduction, or acidity increase/decrease, change the final content and proportion of substances presence. Good example are furfural and polyphenols [26].

\section{Conclusions}

1. Infrared spectroscopy as a fast, simple, and non-destructive technique occurred to be useful an effective tool for the identification and discrimination of different whiskies due to their origin and age.

2. IR technique evidenced overall differences in chemical composition among whiskies produced in Scotland, Ireland, and USA.

3. IR technique provided specific enough spectral data to distinguish whiskies maturated for 2, 3, 6, and 12 years meaning appropriate band intensities and wavenumbers are distinct and specific for each sample.

4. Unknown samples can be identified in terms of origin or age with use of constructed in current paper models.

Acknowledgements This publication has been co-financed with the European Union funds by the European Social Fund no 275/ES/ZSIII/W-POKL/14 and the National Science Centre Poland as grant no N N312 463440.

\section{Compliance with ethical standards}

Conflict of interest No conflict of interest has been declared.
Compliance with ethics requirements This article does not contain any studies with human or animal subjects.

Open Access This article is distributed under the terms of the Creative Commons Attribution 4.0 International License (http://creativeco mmons.org/licenses/by/4.0/), which permits unrestricted use, distribution, and reproduction in any medium, provided you give appropriate credit to the original author(s) and the source, provide a link to the Creative Commons license, and indicate if changes were made.

\section{References}

1. Bringhurst T, Brosnan J (2014) Scotch whisky: raw material selection and processing. In: Russell I, Stewart GG (eds) Whisky: technology, production and marketing. Elsevier Ltd, Amsterdam

2. Regulation EC 110 (2008) on the definition, description, presentation, labelling and the protection of geographical indications of spirit drinks and repealing Council Regulation (EEC) No 1576/89

3. Tamaki T, Takamiya Y, Takaesu C, Shimoji M (1986) The classification of unaged and matured awamori by principal component analysis. Hakkokogaku 64:65-70

4. Jackson M (2010) Malt whisky companion, 6th edn. Dorling Kindersley Ltd., London

5. Nagato L, Duran M, Caruso M, Barsotti R, Badolato E (2001) Monitoramento da autenticidade de amostras de bebidas alcohólicas enviadas ao instituto Adolfo Lutz en Sao Paulo. Cien Tec Alimen 21:54-62

6. Novakowski W, Bertotti M, Paixão TRLC (2013) Use of copper and gold electrodes as sensitive elements for fabrication of an electronic tongue: discrimination of wines and whiskies. Microchem J 99:145-151

7. Cantarelli M, Azcarate SM, Savio M, Marchevsky EJ, Camiña JM (2015) Authentication and discrimination of whiskies of high commercial value by pattern recognition. Food Anal Methods 8(3):790-798

8. Legin A, Rudnitskaya A, Seleznev B, Vlasov Yu (2005) Electronic tongue for quality assessment of ethanol, vodka and eau-de-vie. Anal Chim Acta 534:129-135

9. Câmara JS, Marques JC, Perestrelo RM, Rodrigues F, Oliveira L, Andrade P, Caldiera M (2007) Comparative study of the whisky aroma profile based on headspace solid phase microextraction using different fibre coating. J Chromatogr A 1150:198-207 
10. Ragazzo-Sanchez JA, Chalierb P, Chevalier D, Calderon-Santoyoa M, Ghommidhc C (2008) Identification of different alcoholic beverages by electronic nose coupled to GC. Sens Actuators B 134:43-48

11. Heller M, Vitali L, Leal Oliveira MA, Costa ACO, Micke GA (2011) A rapid sample screening method for authenticity control of whiskey using capillary electrophoresis with online preconcentration. J Agric Food Chem 59:6882-6888

12. Cheng P, Fan W, Yan Xu Y (2013) Quality grade discrimination of Chinese strong aroma type liquors using mass spectrometry and multivariate analysis. Food Res Int 54:1753-1760

13. Stremel Azevedo M, Pirassol G, Fett R, Micke GA, Vitali L, Oliveira Costa AC (2014) Screening and determination of aliphatic organic acids in commercial Brazilian sugarcane spirits employing a new method involving capillary electrophoresis and a semi-permanent adsorbed polymer coating. Food Res Int 60:123-130

14. Uríčková V, Sádecká J (2015) Determination of geographical origin of alcoholic beverages using ultraviolet, visible and infrared spectroscopy: a review. Spectrochim Acta A 148:131-137

15. MacKenzie WM, Aylott RI (2004) Analytical strategies to confirm Scotch whisky authenticity. Part II: Mobile brand authentication. Analyst 129:607-612

16. Mignani AG, Ciaccheri L, Gordillo B, Azelio Mencaglia A, González-Miret ML, Heredia FJ, Culshaw B (2012) Identifying the production region of single-malt Scotch whiskies using optical spectroscopy and pattern recognition techniques. Sens Actuators B 171-172:458-462

17. Martins AR, Talhavini M, Vieira ML, Zacca JJ, Batista Braga JW (2017) Discrimination of whisky brands and counterfeit identification by UV-Vis spectroscopy and multivariate data analysis. Food Chem 229:142-151

18. Sujka K, Reder M, Ciemniewska-Żytkiewicz H, Koczoń P (2014) FT-IR spectroscopy and discriminant analysis applied to identify raw material used in production of vodka. Bromat Chem Toksykol XLVII 3:760-764

19. Sujka K, Reder M, Koczoń P (2012) The application of FT-IR spectroscopy for identification and discrimination of selected spirit beverages. Bromat CHEM Toksykol XLV 3:383-389

20. Sujka K, Koczoń P, Górska A, Wirkowska M, Reder M (2013) Sensory and spectral characteristics of selected freeze-dried spirit beverages. Zywn-Nauk Technol Ja 4(89):184-194

21. Wiśniewska $\mathrm{P}$, Boqué $\mathrm{R}$, Borràs $\mathrm{E}$, Busto $\mathrm{O}$, Wardencki W, Namieśnik J, Dymerski T (2017) Authentication of whisky due to its botanical origin and way of production by instrumental analysis and multivariate classification methods. Spectrochim Acta A 173:849-853

22. Silverstein RM, Webster FX, Kremle DJ (2007) Spectrometric identification of organic compounds. PWN Ltd., Warsaw 72-108

23. Linstrom PJ, Mallard WG (2013) NIST chemistry webbook, NIST standard reference database number 69. National Institute of Standards and Technology, MD, Gaithersburg, p 20899

24. González-Arjona D, González-Gallero V, Pablos F, González AG (1999) Authentication and differentiation of irish whiskeys by higher-alcohol congener analysis. Anal Chim Acta 381:257-264

25. The Scotch Whisky Regulations 2890 (2009)

26. Collins TS, Zweigenbaum J, Ebeler SE (2014) Profiling of nonvolatiles in whiskeys using ultra high pressure liquid chromatography quadrupole time-of-flight mass spectrometry (UHPLC-QTOF MS). Food Chem 163:186-196 